\title{
Comparative study between Johnson's formula and Dare's formula of fetal weight estimation at term
}

\author{
Anitha C.*, Deepa V. Kanagal \\ Department of Obstetrics and Gynecology, Father Muller Medical College, Mangalore, Karnataka, India
}

Received: 12 June 2021

Revised: 18 July 2021

Accepted: 19 July 2021

\section{*Correspondence:}

Dr. Anitha C.,

E-mail: dranitha021088@gmail.com

Copyright: $\odot$ the author(s), publisher and licensee Medip Academy. This is an open-access article distributed under the terms of the Creative Commons Attribution Non-Commercial License, which permits unrestricted non-commercial use, distribution, and reproduction in any medium, provided the original work is properly cited.

\begin{abstract}
Background: Prediction of fetal weight is one of the methods towards effective management of pregnancy and delivery. To assess and compare the accuracy of clinical and sonographic fetal weight estimation in predicting birth weight at term pregnancy, patients who were in latent or in active phase of labour. In the present study, an effort is made to compare two different clinical methods and USG and relate to the actual weight of the baby at birth.

Methods: It is a prospective observational study of one hundred pregnant women satisfying the criteria, consenting for the study was recruited. Both USG and clinical methods will be done and compared with estimated the fetal weight. Weight of the baby at birth will be measured.

Results: All the three methods had significant relationship with the baby weight. Percentage error was least with USG and the standard deviation of error was lower with Dare's formula. The standard deviation was minimal for Dare's formula EFW followed closely by USG.

Conclusions: It can be concluded that Dare's formula of clinical methods can be a potential option to be promoted in predicting the fetal weight in the absence of USG facilities. Training in this method is very important and can be an integral part in managing pregnancy during delivery in primary care setting.
\end{abstract}

Keywords: Dare's formula, Johnson's formula, Fetal weight at term pregnancy, Prediction, Ultrasonography

\section{INTRODUCTION}

Accurate estimation of fetal weight is one of the important aspects in the management of labor. It is emphasized that birth weight is an important parameter for perinatal morbidity and mortality. Categorization of fetus into small or large for gestation age will help in timely obstetric management. ${ }^{1}$ Estimating fetal weight is also important when dealing with preterm births where counselling regarding the prognosis, survival of the newborn and need for intensive care depends on fetal weight. Extremes of birth weight are both associated with increased risk of neonatal morbidity during labor and postpartum period. The potential complications of large fetus associated with vaginal delivery include shoulder dystocia, brachial plexus injury, bone injuries, and intrapartum asphyxia, while the maternal risks include birth canal and pelvic floor injuries, increased rate of operative vaginal and cesarean deliveries, and postpartum haemorrhage. ${ }^{1}$ Abnormalities in fetal growth can be detected clinically or by ultrasound. Simple methods like measurement of symphysio- fundal height and abdominal girth can be used to predict expected fetal weight in low resource settings.

The occurrence of cephalopelvic disproportion is more prevalent with increasing fetal size and contributes to both an increased rate of operative vaginal delivery and cesarean delivery for macrosomic fetuses compared with fetuses of normal weight. ${ }^{4}$ 
Fetal weight is also important in assessing whether the fetus is small for gestational age or large for gestational age in order to have a good obstetrical decision making and also to avoid intrapartum distress and birth trauma and thereby to reduce neonatal morbidity and mortality. ${ }^{3}$

Also, estimation of fetal weight play a vital role in the management of diabetic pregnancy, vaginal delivery after cesarean section (VBAC) and intrapartum management of fetus with breech presentation. ${ }^{1}$ The two main methods for predicting birthweight in current obstetrics are: clinical techniques based on abdominal palpation of foetal parts and calculations based on fundal height and sonographic measures of skeletal fetal parts. ${ }^{2}$

Ultrasound is also used for estimation for expected fetal weight and diagnosis of impaired growth. But, it may not be available in all health centres offering obstetric care, especially in low resources settings. Fetal weight estimation using ultrasound needs training, expertise and expensive equipment. In such circumstances clinical methods of estimating fetal weight can aid in obstetric decision making. ${ }^{2}$

Therefore, development and validation of simple, inexpensive, accurate and effective clinical methods are important especially in countries like India, where equipment and trained manpower are scarce at most places of delivery.

\section{Aim and objectives}

The aim of this study was to determine which method of fetal weight estimation (clinical or sonographic) is more accurate. This will help in appropriate decision making in the management of the pregnant woman. ${ }^{2}$ Johnson's and Dare's formula's to estimate the fetal weight in comparison with ultrasound estimated fetal weight and actual birth weight

\section{METHODS}

It was a prospective observational study conducted in the department of obstetrics and gynecology, Father Muller medical college, Mangalore, between April 2019 to June 2019. 102 women during pregnancy who came to the antenatal ward in early labour or for induction or elective LSCS at Father Muller medical college Mangalore were included in the study. The sample size was determined using the formula mentioned below where $\mathrm{p}=0.69$.

$$
\mathrm{n}=\frac{\mathrm{Z} \alpha^{2} p(1-p)}{e^{2}}
$$

\section{Inclusion criteria}

Inclusion criteria for current study were; age more than 18 years. Singleton pregnancy, cephalic presentation, live fetus, known last menstrual period or scan with continued expected date of delivery and gestational age $\geq 37$ weeks and $\leq 42$ weeks.

\section{Exclusion criteria}

Exclusion criteria for current study were; multiple gestation, non-cephalic presentation, anomalous fetus, intrauterine fetal death, presence oh co-existing fibroids, ovarian cysts and already diagnosed liquor abnormalities.

At admission after a brief general physical examination, per abdominal examination was performed in supine position. Patient was asked to empty the bladder before examination, the fundal height was palpated from xiphisternum downwards after correction of dextrorotation of the uterus. SFH is measured using a measuring tape from the highest point in the uterine fundus after correcting the rotation to the midpoint of upper border of pubic symphysis. This was followed by measurement of abdominal girth in centimetre at the level of umbilicus.

Expected fetal weight was calculated using two clinical formula, Johnson's formula and Dare's formula. Estimation of fetal weight by ultrasound was done within 2 days of clinical examination. The fetal weight was estimated within a week prior to the delivery. The patient may be delivered either by vaginal route or by cesarean section.

The maximum delivery interval after USG and clinical estimation may be $48 \mathrm{hrs}$. After birth, the actual birth weight was measured using standard digital weighing machine. The expected fetal weight by clinical formula and ultrasound weight were compared with the actual birth weight.

\section{Johnson 's formula}

$$
\text { Fetal weight }(\mathrm{gms})=(\mathrm{SFH}-\mathrm{X}) \times 155
$$

Where $\mathrm{X}$ is 12 if the vertex is above 0 station and $\mathrm{X}$ is 11 if station is below 0 station.

\section{Dare's formula}

$$
\text { Fetal weight }(\mathrm{gms})=\mathrm{SFH} \times \mathrm{AG}
$$

\section{RESULTS}

Out of 102 samples, $44 \%$ of women were primigravida and $66 \%$ were multigravida. 66 patients underwent normal vaginal delivery and 36 patients underwent cesarean section. Distribution of study subjects in relation to age showed that majority of them were in the age group 25-29 years followed by 20-24 years (Table 3). The number of subjects examined at 37 weeks term pregnancy was 23,21 were at 38 weeks, 36 were at 39 and 22 were at 40 weeks (Table 2). The mean value of fetal weight derived by Dare's formula from clinical method was $3129.19 \pm 315.58 \mathrm{gm}$, the mean value of fetal 
weight estimated by USG was $3091 \pm 430 \mathrm{gm}$ and the actual baby weight at birth was $3169 \pm 490.3 \mathrm{gm}$. Correlation co-efficient was highest (0.951) with Dare's, followed by USG (0.721) and Johnson's method (0.78). Corresponding standard error with the respective method was $357.7,360.7$ and $389.8 \mathrm{gm}$. The percentage of cases that could be correctly predicted by USG was 66.9. The mean value of fetal weight derived by Dare's formula from clinical method was $3363.2 \pm 487.8 \mathrm{gm}$ and $68.7 \%$ of cases could be correctly predicted by this method.

Table 1: Distribution of patients by birth weight.

\begin{tabular}{|ll|}
\hline Birth weight $(\mathbf{g})$ & N \\
\hline $\mathbf{2 0 0 1 - 2 5 0 0}$ & 10 \\
\hline $\mathbf{2 5 0 1 - 3 0 0 0}$ & 29 \\
\hline $\mathbf{3 0 0 1 - 3 5 0 0}$ & 49 \\
\hline $\mathbf{> 3 5 0 0}$ & 14 \\
\hline Total & 102 \\
\hline
\end{tabular}

Table 2: Distribution of study subjects in relation by period of gestation.

\begin{tabular}{|l|l|}
\hline Period of gestation (weeks) & N \\
\hline 37 & 23 \\
\hline 38 & 21 \\
\hline 39 & 36 \\
\hline $\mathbf{4 0}$ & 22 \\
\hline Total & 102 \\
\hline
\end{tabular}

Table 3: Distribution of patients by age.

\begin{tabular}{|ll|}
\hline Age group (years) & N \\
\hline Below 19 & 3 \\
\hline $\mathbf{2 0 - 2 4}$ & 29 \\
\hline $\mathbf{2 5 - 2 9}$ & 47 \\
\hline $\mathbf{3 0 - 3 4}$ & 20 \\
\hline $\mathbf{3 5}$ and above & 3 \\
\hline Total & 102 \\
\hline
\end{tabular}

Table 4: Mode of delivery.

\begin{tabular}{|ll|}
\hline Mode of delivery & N \\
\hline Normal & 66 \\
\hline Caesarean & 36 \\
\hline Total & 102 \\
\hline
\end{tabular}

Table 5: Birth weight in relation to gravid.

\begin{tabular}{|llllll|}
\hline Gravida & $\begin{array}{l}<.5 \\
\mathrm{~kg}\end{array}$ & $\begin{array}{l}\mathbf{2 . 5 - 3} \\
\mathrm{kg}\end{array}$ & $\begin{array}{l}\mathbf{3 - 3 . 5} \\
\mathbf{k g}\end{array}$ & $\begin{array}{l}>\mathbf{3 . 5} \\
\mathbf{k g}\end{array}$ & Total \\
\hline $\mathbf{1}$ & 7 & 11 & 20 & 6 & 44 \\
\hline $\mathbf{2}$ & 2 & 12 & 16 & 4 & 34 \\
\hline $\mathbf{3}$ & 1 & 4 & 9 & 3 & 17 \\
\hline $\mathbf{4}$ & 0 & 4 & 2 & 1 & 7 \\
\hline Total & 10 & 31 & 47 & 14 & 102 \\
\hline
\end{tabular}

Table 6: Paired $t$ test for comparison of the estimated and actual weight in each sample separately.

\begin{tabular}{|c|c|c|c|c|c|}
\hline Pairs & & $\mathbf{N}$ & Mean & SD & $\begin{array}{l}\mathbf{P} \\
\text { value }\end{array}$ \\
\hline \multirow{2}{*}{1} & $\begin{array}{l}\text { USG } \\
\text { weight }\end{array}$ & 102 & 3004.3 & 322.963 & \multirow{2}{*}{0.011} \\
\hline & $\begin{array}{l}\text { Birth } \\
\text { weight }\end{array}$ & 102 & 3069.61 & 353.34 & \\
\hline \multirow[b]{2}{*}{2} & Johnson & 102 & 3047.06 & 306.664 & \multirow[b]{2}{*}{0.31} \\
\hline & $\begin{array}{l}\text { Birth } \\
\text { weight }\end{array}$ & 102 & 3069.61 & 353.34 & \\
\hline \multirow[b]{2}{*}{3} & Dares & 102 & 3129 & 315.585 & \multirow[b]{2}{*}{$\leq 0.001$} \\
\hline & $\begin{array}{l}\text { Birth } \\
\text { weight }\end{array}$ & 102 & 3069.61 & 353.34 & \\
\hline
\end{tabular}

Total 66 patients underwent normal vaginal delivery and 36 patients underwent cesarean section. On comparison of the mean values of Johnson formula and birth weight the mean values of birth weight is higher with a difference of 22.549 is statistically not significant with a $\mathrm{p}$ value of 0.31 . On comparison of the mean values of Dare's and birth weight the mean values of Dare's is higher with a difference of 59.578 is statistically significant with $\mathrm{p}<0.001$. The correlation between the parameters Dare's and birth weight shows a excellent positive correlation, and is significant with $p<0.001$. The mean average error represents the sum of the positive (overestimation) and the negative (underestimation) from actual birth weight. The standard deviation of errors was 254.005, 110.748 and 223.304 by USG, Dare's and Johnson's method. Dares has very less underestimation, Johnson and USG have many cases of underestimation.

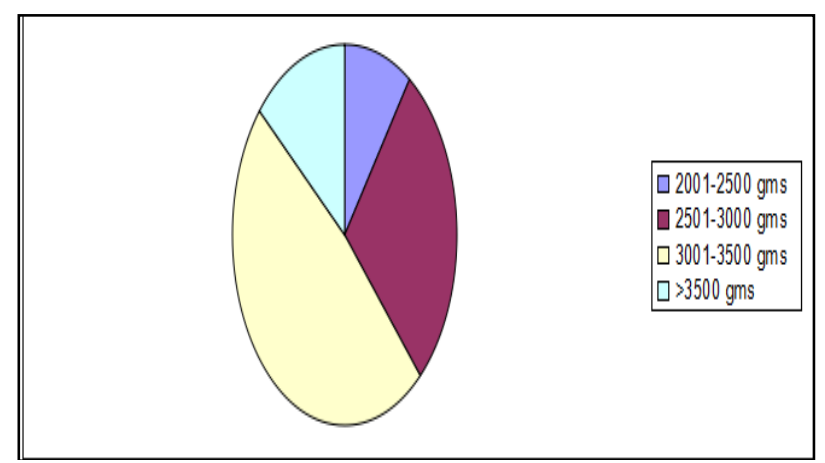

Figure 1: Distribution of patients by birth weight.

\section{DISCUSSION}

The ultimate aim of obstetric practice is delivery of a healthy baby with least amount of maternal morbidity. Birth weight assumes importance in that its accurate estimation in-utero gives a fairly good estimate of the neonatal outcomes. In addition, it is of value in the management of breech presentations, diabetes mellitus, trial of labour, macrosomic fetuses and multiple births. ${ }^{7}$ 
Table 7: Percentage error of predicted value against the actual baby weight by different methods.

\begin{tabular}{|lllllll|}
\hline Parameters & $\begin{array}{l}\text { Error } \\
\text { Dares }\end{array}$ & $\begin{array}{l}\text { Valid } \\
\text { percent }\end{array}$ & $\begin{array}{l}\text { Error } \\
\text { Johnson }\end{array}$ & $\begin{array}{l}\text { Valid } \\
\text { percent }\end{array}$ & $\begin{array}{l}\text { Error } \\
\text { USG WT }\end{array}$ & $\begin{array}{l}\text { Valid } \\
\text { percent }\end{array}$ \\
\hline Overestimation >100gms & 29 & 28.4 & 29 & 28.4 & 28 & 27.5 \\
\hline Overestimation 0-100gms & 37 & 36.3 & 14 & 13.7 & 11 & 10.8 \\
\hline Accurate & 4 & 3.9 & 11 & 10.8 & 6 & 5.9 \\
\hline Underestimation 0-100 gms & 28 & 27.5 & 16 & 15.7 & 11 & 10.8 \\
\hline Underestimation $>\mathbf{1 0 0}$ gms & 4 & 3.9 & 32 & 31.4 & 46 & 45.1 \\
\hline Total (\%) & 102 & 100 & 102 & 100 & 102 & 100 \\
\hline
\end{tabular}

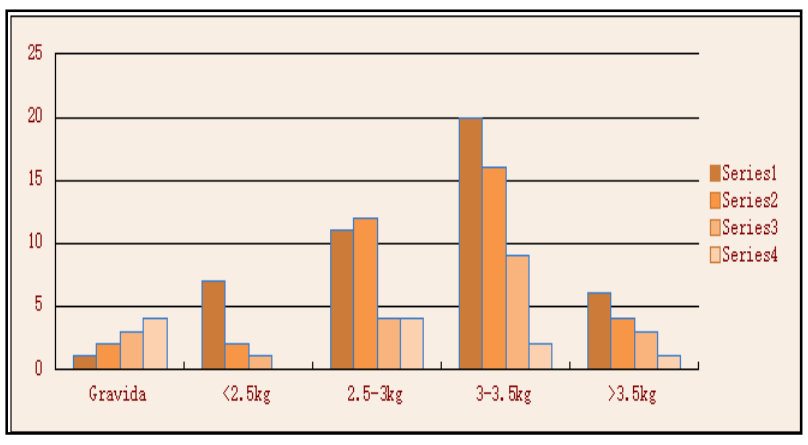

Figure 2: Birth weight in relation to gravid.

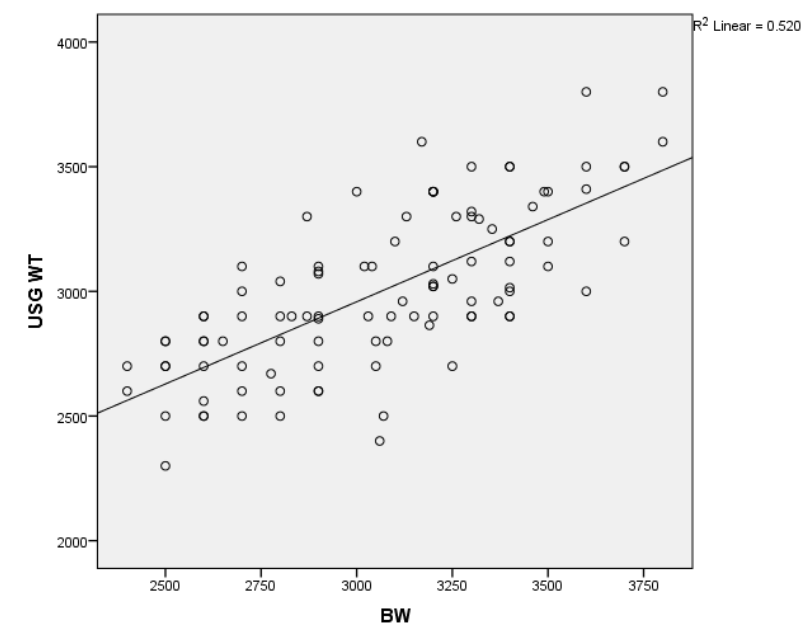

Figure 3: Relation between estimated fetus weight by USG and baby weight at birth.

The mean value of fetal weight derived by Dare's formula from clinical method was $3129.19 \pm 315.58 \mathrm{gm}$, the mean value of fetal weight estimated by USG was $3091 \pm 430 \mathrm{gm}$ and the actual baby weight at birth was $3169 \pm 490.3 \mathrm{gm}$. Majority of the babies were within the range of $3-3.5 \mathrm{~kg}$ birth weight. The results of the present study concluded that the predicted fetal weight significantly correlated with the actual birth weight by all the three (USG, Dare's and Johnson's) methods. 68.7\% of cases could be correctly predicted by this method. In our study, average maximum error was the least by Dares method followed by Hadlock's ultrasound method. The estimation of intrauterine fetal weight is the vital component in deciding the management of labor and delivery, and also their measurements are more useful especially in managing fetuses in breech presentation or suspicious of having macrosomia. Clinicians frequently estimate fetal weight when examining women in labor at term. This may help in predicting cephalopelvic disproportion when labor progress is poor, or gives early warning of possible shoulder dystocia. Correlation coefficient with the actual baby weight was close in all the methods with the highest being Dare's method.

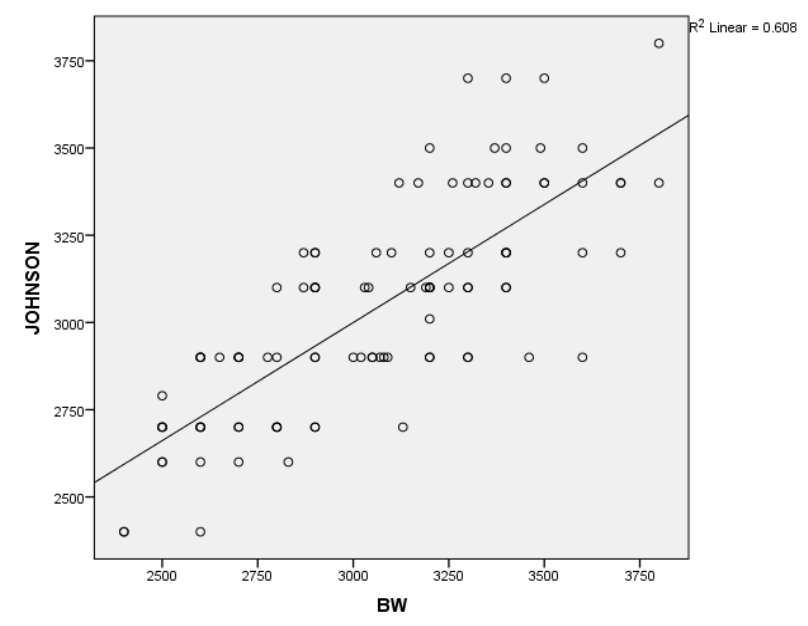

Figure 4: Relation between estimated fetus weight by Johnson's formula and baby weight at birth.

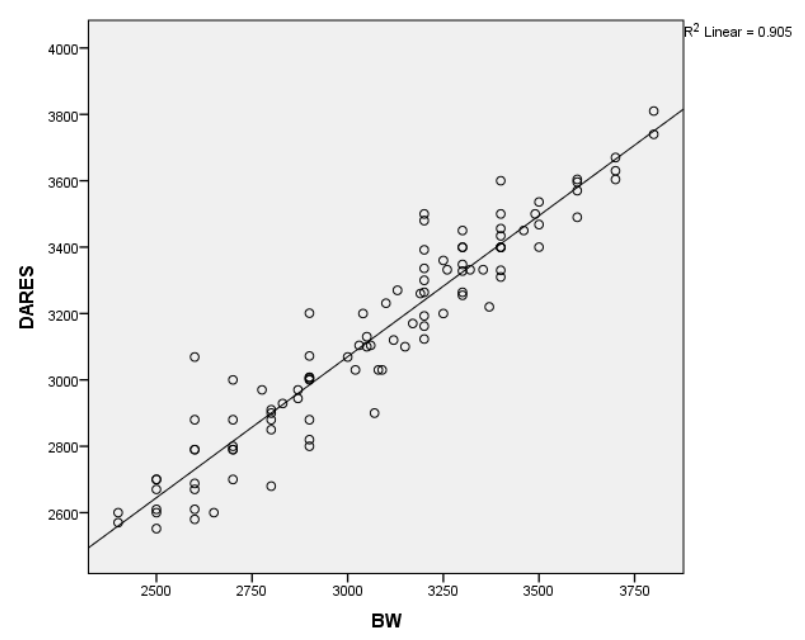

Figure 5: Relation between estimated fetus weight by Dare's formula and baby weight at birth. 
Correlation co-efficient was highest (0.951) with DARES and BW, followed by USG WT and BW(0.721) and Johnson's method (0.78). Parvathavarthini et al concluded that the percentage error was $6.4 \%$ by USG and it was higher by Dare's method $(12.5 \%)$ as well as Johnson's method (16.0\%). Maximum error in USG was 1120 while it was 1172 by Dare's method and 1485 by Johnson's method. The standard deviation of errors was 396.4, 382.6 and 430.9 by USG, Dare's and Johnson's method. The percentage error was relatively higher in Johnson's method, followed by Dare's method and it was least by USG. ${ }^{1}$ Amritha et al found the average error by Dares was $224.37 \mathrm{~g}$ which was least when compared to Johnson's and Hadlock's method. In the present study, the average error was least by Dares formula, which was $56.12 \mathrm{~g}$ followed by Hadlock's formula (100.245 g) and Johnson's formula (393.26 g). ${ }^{4}$

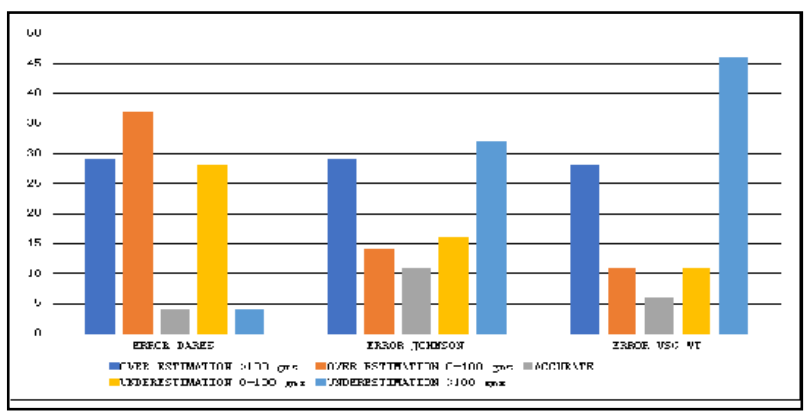

Figure 6: Number of cases showing under and over estimates by percentage in different methods.

In a study conducted by Kathiriya et al in 2014 concluded that the mean percentage of error was $248.2 \mathrm{~g}$ and 13.48 percentages for insler EFW, 265.2 $\mathrm{g}$ and 14.36 percentages for hadlock EFW, $573 \mathrm{~g}$ and 31 percentages for Johnson formula. The proportion of the EFW which were within 10 percentage of birth weight was 66.6 percentage for insler formula, 70 percentage for Hadlock formula and 22.4 percentage for Johnson formula. Insler and Hadlock EFW were correlated well with actual birth weight, as compare to Johnson formula that had a highest error in prediction of birth weight. ${ }^{3}$

Tiwari and Sood in their study showed an average error of $364.96 \mathrm{~g}, 327.28 \mathrm{~g}$, and $198.6 \mathrm{~g}$ by Dares, Johnson's, and Hadlock's ultrasound method, respectively. ${ }^{5}$ Standard deviation of prediction error. The standard deviation was minimal for Dare`s formula EFW followed closely by USG. The maximum standard deviation was present for Johnson's formula and USG. Sherman et al. reported that percentage of fetal weight estimates falling within $10 \%$ margin of error for clinical and USG method was $72 \%$ and $69 \%$, respectively. ${ }^{6}$ Amritha et al reported the same to be $67 \%$ and $62 \%$ for Dares method and USG method, respectively. ${ }^{4}$ Several technical limitations of the sonographic technique for estimating foetal weight are well-known. Among these are maternal obesity, oligohydramnios, and anterior placentation. Other disadvantages of ultrasonography are that it is both complicated and labour intensive, potentially being limited by suboptimal visualization of foetal structure. It also requires costly sonographic equipment and specially trained personnel. Although such expensive imaging equipment is widely available in developed countries, this is generally not the case in developing nations like ours where medical resources are scarce. ${ }^{8-9}$

\section{Limitations}

Dare's method is limited to only singleton pregnancy. The main limitation of this study is that the SFH was measured by various health personnel. Therefore, it may cause measurement bias affecting validity of our study. However, those personnel were trained and qualified to do this task. However, clinical methods have limitations of their own subject to inter individual variation depending on the observer in addition to errors inherent to the technique.

\section{CONCLUSION}

Thus, based on this study, Dares clinical formula can be of great value in a developing country like ours, where ultrasound is not available at many healthcare delivery systems. It is easy, cost-effective and simple and can be used even by midwives. From the results of the present study, it can be concluded that Dare's method is superior to Johnson's method and equally good as USG in predicting the fetal weight. The minimal standard deviation of error with Dare's method makes it even better than USG. Also, Dare's method can be easily taught to the midwives. This clinical method is also a quick, effective and inexpensive technique in calculating the fetal weight even by less experienced person especially in areas of low resource setting.

\section{Funding: No funding sources}

Conflict of interest: None declared

Ethical approval: The study was approved by the Institutional Ethics Committee

\section{REFERENCES}

1. Parvathavarthini $\mathrm{K}$. Comparative study of various methods of fetal weight estimation at term pregnancy in a tertiary hospital in Kanchipuram, Tamil nadu, India. Int J Reprod Contracept Obstet Gynecol. 2018;7(4):1602-7.

2. Roy AG, Kathaley MH. Comparison of estimation of fetal weight by clinical method, ultrasonography and its correlation with actual birth weight in term pregnancy. MVP J Med Sci. 2018;5(1):75-81.

3. Kathiriya D. Comparative study of various methods of fetal weight estimation at term pregnancy. Int J Rec Trends Sci Technol. 2014;9(3):453-6.

4. Amritha BA, Patric PJ, Ashwin SP. Comparative study of various methods of fetal weight estimation at term pregnancy. J Obstet Gynecol. 2004;54:336-9.

5. Tiwari R, Sood M. Comparative study of various 
methods of fetal weight estimation at term pregnancy. J Obstet Gynecol. 1989;39:279-86.

6. Sherman DJ, Arifli S, Tovbin J, Siegel G, Caspi E, Bukovsky I. A comparison of clinical and ultrasonic estimation of fetal weight. Obstet Gynecol. 1998;91: 212-7.

7. Chauhan SP. Intrapartum detection of a macrosomic fetus: Clinical versus and sonographic models. J Obstet Gynecol. 1995;35:266-70.

8. Nzeh DA, Rimmar S, Moore WMO, Hunt L. Prediction of birth weight by fetal ultrasound biometry. Br J Radiol. 1992;66:987-9.

9. Mehdizadeh A, Alaghehbandan R, Horsan H. Comparison of clinical versus ultrasound estimation of fetal weight. Am J Perinatol. 2000;17:233-6.

Cite this article as: Anitha C, Kanagal DV.

Comparative study between Johnson's formula and Dare's formula of fetal weight estimation at term. Int J Reprod Contracept Obstet Gynecol 2021;10:341823 